\title{
Latihan Sirkuit 5 Pos Untuk Meningkatkan Kebugaran Jasmani Siswa Dimasa Pandemi
}

\section{Post Circuit Exercises to Improve Students' Physical Fitness During the Pandemic}

\author{
Andy Supriady \\ Program studi PJKR, STKIP Pasundan, Jalan Permana No. 32B Kota Cimahi, Jawa Barat, \\ 40553, Indonesia
}

\begin{abstract}
Abstrak
Tujuan penelitian ini adalah untuk melihat pengaruh latihan Sirkuit 5 Poss yang terdiri dari; Pos (1) push up; Pos (2) sit up; Pos (3) jumping jack; Pos (4) mountain climber; Pos (5) wall sheet untuk meningkatkan kebugaran jasmani siswa dimasa pandemi. Metode yang digunkan adalah ekperimen dengan desain penelitian one group pre-post test desain. Populasi dan sampel pada penelitian ini adalah 20 siswa kelas 8A SMPN Padalarang. Instrumen yang digunakan adalah Tes Kebugaran Jasmani Indonesia untuk tingkat sekolah menengah pertama (SMP) terdiri dari: 1) Tes lari cepat 50 meter; 2)Tes angkat tubuh 30 detik; 3) Tes baring duduk 60 detik; 4) Tes loncat tegak; 5) Tes lari jarak jauh 1000 meter. Hasil analisis dari 5 item tes kebugaran jasmani dengan t-hitung 1,55 dan ttabel 2,23 dengan signifikansi $5 \%(\alpha=0,05)$ dengan rata-rata kategori sedang. Maka dapat disimpulkan bahwa latihan sirkuit 5 pos dan latihan cross country memberikan pengaruh yang signifikan terhadap peningkatan kebugaran jasmani siswa dimasa pandemi.
\end{abstract}

Kata kunci: Kebugaran jasmani, Sirkuit 5 Pos

\begin{abstract}
The purpose of this study was to see the effect of the 5 Poss Circuit exercise consisting of; Post (1) push ups; Post (2) sit ups; Heading (3) jumping jacks; Post (4) mountain climber; Pos (5) wall sheet to improve students' physical fitness during the pandemic. The method used is an experimental research design with one group pre-post test design. The population and sample in this study were 20 students of class 8A SMPN Padalarang. The instrument used was the Indonesian Physical Fitness Test for junior high school (SMP) level consisting of: 1) 50 meter sprint test; 2) 30 second body lift test; 3) 60 second lying down test; 4) Vertical jump test; 5) 1000 meter long distance running test. The results of the analysis of 5 physical fitness test items with $t$-count 1.55 and $t$-table 2.23 with a significance of $5 \%(\alpha=0.05)$ with an average category of being. It can be concluded that the 5 post circuit training and cross-country training have a significant effect on increasing students' physical fitness during the pandemic.
\end{abstract}

Keywords: Physical fitness, 5 Post Circuit 


\section{PENDAHULUAN}

Kebugaran jasmani merupakan faktor utama yang mempengaruhui status kesehatan setiap individu. Kebugaran jasmani dapat diartikan sebagai kemampuan seseorang dalam melakukan suatu tugas gerak tertentu secara maksimal dan efisein tanpa maengalami kelelahan yang berlebihan serta terhindar dari resiko ganguan kesehatan (Bile \& Tapo, 2021). Pada masa Pandemi Covid-19 pemeliharaan kebugaran jasmani harus tetap dilakukan sebagai salah satu tindakan preventif dalam rangka meningkatkan imunitas tubuh serta untuk pemeliharaan kesehatan secara umum (Sukur et al., 2020). Manfaat kebugaran jasmani akan berkontribusi besar dengan aktifitas yang dilakukan setiap individu dalam kehidupan sehari-hari. Kebugaran jasmani ini sangat berpengaruh terhadap proses tumbuh kembang anak, karena tingkat kebugaran jasmani seseorang menentukan kemampuan fisiknya dalam menjalani kehidupan sehari-harinya (Sinuraya \& Barus, 2020). Semakin bagus tingkat kebugaran jasmani seseorang, semakin tinggi pula kemampuan kerja fisiknya (Purba, Jumesli, Atri Widowati, 2020). Sekolah sebagai lembaga formal yang dimulai dari tingkat sekolah dasar hingga tingkat perguruan tinggi, merupakan sarana yang tepat dalam membentuk kebugaran jasmani anak. Semua kegiatan kebugaran jasmani direncanakan dan diarahkan, agar tujuan yang telah ditetapkan menghasilkan pencapaian perubahan sikap yang positif pada siswa. Dengan kebugaran jasmani yang baik diharapkan siswa mampu belajar dengan semangat, tidak mudah terserang penyakit, berprestasi secara optimal, dan mampu menghadapi tantangan baik di sekolah maupun luar sekolah.

Salah satu tujuan umum dari pendidikan jasmani adalah perkembangan fisik (Ariestika et al., 2021). Artinya melalui pendidikan jasmani ini diharapkan anak dapat memiliki tingkat kebugaran jasmani yang baik dan meningkat. Manfaat yang dapat diambil dengan memiliki tingkat kebugaran jasmani salah satunya adalah tubuh akan mampu melakukan tugas gerak tanpa akan mengalami kelelahan dalam tubuh sehingga dapat mendatangkan cidera yang menimbulkan sakit dalam tubuh (SHAPE America, 2015). Proses pembelajaran pendidikan jasmani disekolah pada masa pandemi tetap dapat dilaksakan sehingga tujuan pendidikan dapat dicapai dengan pemanfaat teknologi informasi (Pakpahan, 2020). Kemudahan dalam melakukan akses informasi materi pembelajaran secara online melalui media smart phone, komputer dan media elektronik lainnya secara tidak langsung berimplikasi pada kondisi rendahnya kinerja aktivitas fisik. Kondisi ini dapat menimbulkan kecendrungan pola hidup yang akan meningkatkan resiko ganguan kesehatan seperti obesits, gangguan sisteam kardiovasular, berkurangnya imunitas tubuh serta penyakit lainnya (Murtiningsih, 2020). Tidak dipungkiri bahwa 
wabah covid-19 mengharuskan siswa belajar dari rumah sehingga berdampaka pada kurangnya intensitas aktivitas fisik pelajar pada umumnya tidak terkecuali siswa tingkat menengah pertama.

Kebugaran jasmani memberikan gambaran bahwa pola hidup sehat, aktif dan tidak aktifnya orang, status kesehatan dan percaya diri seseorang dipengaruhi oleh kebugaran jasmani. Siswa yang memiliki kebugaran yang baik ternyata aktif ketika jam istirahat dengan kegiatan olahraga atau menari (Chen et al., 2018). Program yang dicanangkan oleh kamapus memberikan efek yang baik terhadap tingkat aktivitas jasmani dan efektif menurunkan BMI (Ickes et al., 2016). Untuk mendidik agar siswa berperilaku hidup aktif perlu direncanakan dan diprogramkan olahraga, aktivitas jasmani, ritmik dan aktivitas outdoor dengan mendesain lingkungan dan memberikan pemahaman, kesadaran secara kognitif agar memotivasi secara internal kaitannya dengan aktivitas jasmani(Ennis, 2017). Terbukti bahwa siswa yang aktif ternyata level kebugaran, rasa percara diri dan orientasi hidup lebih baik dibandingkan dengan siswa yang kurang aktif (Ahmed et al., 2018). Berdasarkan beberapa penelitian ini memberikan bukti bahwa agar siswa hidup aktif harus diajarkan, ada program ada motivasi. Hidup aktif dipengaruhi oleh proses belajar di sekolah, maka sekolah harus memberikan pelayanan yang baik. Untuk bugar diperlukan keikutsertaan dalam kegiatan aktivitas jaasmani, baik berupa kegiatan olahraga atuapun rekreasi yang menggunakan aktivitas jasmani. Upaya untuk menjadi bugar dalam beraktivitas jasmani memerlukan pemahaman tentang intensitas latihan dan metode latihannya.

Metode latihan yang dapat digunakan untuk meningkatkan kebugaran jasmani diantaranya adalah: lari lintas alam, fartlek, interval training dan sirkuit training. Salah satu program latihan fisik yang mudah dan tidak memerlukan waktu yang lama adalah program latihan sirkuit (Afdinda et al., 2021). Latihan sirkuit merupakan bentuk latihan yang terdiri dari beberapa macam item latihan fisik yang dilakukan secara berkelanjutan tanpa ada jeda atau masa. Sirkuit training ini adalah jenis latihan fisik yang cenderung dilakukan secara urut dan berkelanjutan. Sirkuit training juga sering disebut sebagai latihan singkat namun efektif untuk dilakukan. Latihan sirkuit ini dapat dikombinasikan kebeberapa bentuk latihan mulai dari latihan kekuatan, kelincahan, kecepatan, daya tahan hingga latihan aerobik sekalipun (Alficandra et al., 2019). Latihan sirkuit 5 pos, memberikan variasi latihan sirkuit yang dapat dilakukan siswa di rumah dalam proses pembelajaran penjas secara daring, harpannya jika sisawa bugar maka daya tahan untuk berkosentrasi dalam belajar dan budaya hidup aktif akan terpelihara dan terinternalisasi. 
Maka penelitian ini berusaha untuk meningkatkan kebugaran siswa dengan menggunakan metode latihan sirkuit yang bervariasi yaitu latihan sirkuit 5 pos.

\section{METODE}

Rancangan dalam penelitian ini adalah One Group Pre-test and Post-test Design, yaitu eksperimen yang dilaksanakan pada satu kelompok saja tanpa kelompok pembanding, kelompok yang di beri perlakuan, tetapi sebelum perlakuan, terlebih dahulu dilakukan test awal (pretest), dan kemudian di beri perlakuan. Perlakuan dilakukan 3 kali dalam seminggu selama 1 bulan (12 kali). setelah itu dilakukan lagi test akhir (posttest), seperti tabel di bawah ini:

Rancangan Penelitian

\begin{tabular}{ccc}
\hline Pre-test & Perlakuan & Post-test \\
\hline Y1 & X & Y2
\end{tabular}

Keterangan:

Y1: Tes awal

$\mathrm{X}$ : Latihan sirkuit 5 Pos

Y2 : Tes akhir

\section{Populasi}

Populasi adalah totalitas semua nilai mungkin, baik hasil menghitung maupun pengukuran kuantitatif atau kualitatif dari pada karakteristik tertentu mengenai sekumpulan objek yang lengkap dan jelas. Populasi dalam penelitian ini adalah siswa kelas 8A SMPN Padalarang Kabupaten Bandung Barat sebanyak 20 orang

\section{Sampel}

Teknik Sampling yang dipilih yaitu dengan purposive sampel. Alas an menggunakan teknik sampel purposive sampling adalah karena tidak semua sampel memiliki kriteria sesuai dengan fenomena yang diteliti. Sehingga Sampel pada penelitian ini berjumlah 20 siswa dalam kategori kebugaran yang baik.

\section{Instrumen}

Instrument penelitian adalah suatu alat yang digunakan mengukur fenomena alam maupun sosial yang diamati. Alat yang digunakan oleh peneliti sebagai alat pengumpulan data menggunakan tes kesegaran jasmani Indonesia untuk tingkat sekolah menengah pertama (SMP) yang dikutip dari Buku Tes dan Pengukuran Olahraga Nurhasan (2000:101) (Maksum, 2012). 


\section{Analisi Data}

Dalam penelitian ini data yang diperoleh melalui tes awal dan tes akhir yang merupakan skor-skor mentah. Untuk mendapatkan kesimpulan serta arti dan makna dari data-data tersebut, selanjutnya penulis olah dengan melakukan pengukuran dan analisis secara statistika. Teknik analisis data yang digunakan pada penelitian ini yaitu analisis deskriptif, digunakan program bantu pengolahan data atau angka yaitu SPSS versi 22 dalam melakukan analisis data.

\section{HASIL DAN PEMBAHASAN}

Deskripsi data merupakan gambaran yang digunakan dalam suatu penelitian. Dalam penelitian deskripsi data ini peneliti menggunakan variabel tunggal, dari pengumpulan data hasil tes awal dan tes akhir dengan jumlah sampel yaitu 20 orang siswa kelas 8A SMPN Padalarang Kabupaten Bandung Barat, pengujian dilakukan dengan menggunakan bantuan program Microsoft Excel dan Statistical Program and Service Solution seri 22.0. Berikut ini disajikan deskripsi dari variabel yang diteliti.

\section{Tes lari cepat 50 meter}

Berdasarkan hasil perhitungan tes lari cepat 50 meter dideskripsikan dalam norma penilaian pada tabel sebagai berikut:

Tabel 1. Norma Penilaian Tes Lari Cepat 50 meter

\begin{tabular}{|c|c|c|}
\hline \multicolumn{2}{|c|}{13 - 15 Tahun } & \multirow{2}{*}{ Nilai } \\
\hline Putra & Putri & \\
\hline Sd - 6.7"' & Sd - 7,7"' & 5 \\
\hline $6,8 "-7,6 "$ & 7,8" - 8,7" & 4 \\
\hline $7,7 "-8,7 "$ & $8,8 "-9,9 "$ & 3 \\
\hline $8,8 "-10,3 "$ & $10,0 "-11,9 "$ & 2 \\
\hline $10,4 "$ - dst & $12,0 ”$ - dst & 1 \\
\hline
\end{tabular}

Berdasarkan hasil perhitungan tes awal dan tes akhir lari cepat 50 meter pada sampel diperoleh data sebagai berikut:

Tabel 2

Hasil Penghitungan Nilai Rata-Rata dan Simpangan Baku Tes Lari Cepat 50 meter

\begin{tabular}{cccccc}
\hline \multirow{2}{*}{ Lari 50 m } & & \multicolumn{2}{c}{ Tes Awal } & \multicolumn{2}{c}{ Tes Akhir } \\
\cline { 3 - 6 } & N & $\begin{array}{c}\text { Rata- } \\
\text { rata }\end{array}$ & $\begin{array}{c}\text { Simpangan } \\
\text { baku }\end{array}$ & $\begin{array}{c}\text { Rata- } \\
\text { rata }\end{array}$ & $\begin{array}{c}\text { Simpangan } \\
\text { baku }\end{array}$ \\
\hline Latihan Sirkuit 5 Pos & 20 & 78,9 & $\mathbf{0 , 4 4}$ & $\mathbf{8 , 5 3}$ & 1,01 \\
\hline
\end{tabular}




\section{Tes Angkat Tubuh 30 detik}

Berdasarkan hasil perhitungan tes angkat tubuh 30 detik dideskripsikan dalam norma penilaian pada tabel sebagai berikut:

Tabel 3. Norma Penilaian Tes Angkat Tubuh 30 detik

\begin{tabular}{ccc}
\hline \multicolumn{2}{c}{ 13 -15 Tahun } & \multirow{2}{*}{ Nilai } \\
\cline { 1 - 2 } Putera & Putri & \\
\hline 16 ke atas & 41 ke atas & 5 \\
\hline $11-15$ & $22-40$ & 4 \\
\hline $6-10$ & $10-21$ & 3 \\
\hline $2-5$ & $3-9$ & 2 \\
\hline $0-1$ & $0-2$ & 1
\end{tabular}

Berdasarkan hasil perhitungan tes awal dan tes akhir angkat tubuh 30 detik pada sampel diperoleh data sebagai berikut:

Tabel 4

Hasil Penghitungan Nilai Rata-Rata dan Simpangan Baku Tes Angkat Tubuh 30 Detik

\begin{tabular}{llllll}
\hline \multirow{2}{*}{ Angkat Tubuh 30 detik } & \multirow{2}{l}{ Tes Awal } & \multicolumn{2}{l}{ Tes Akhir } \\
\cline { 3 - 6 } & Nata- & $\begin{array}{l}\text { Simpangan } \\
\text { rata }\end{array}$ & $\begin{array}{l}\text { Rata- } \\
\text { rata }\end{array}$ & $\begin{array}{l}\text { Simpangan } \\
\text { baku }\end{array}$ \\
\hline Latihan Sirkuit 5 Pos & 20 & $\mathbf{3 , 3 4}$ & $\mathbf{1 1 , 1 6}$ & $\mathbf{2 , 9 1}$ & $\mathbf{8 , 4 4}$ \\
\hline
\end{tabular}

\section{Tes Baring Duduk 60 detik}

Berdasarkan hasil perhitungan tes baring duduk 60 detik dideskripsikan dalam norma penilaian pada tabel sebagai berikut:

Tabel 5. Norma Penilaian Tes Baring Duduk 60 detik

\begin{tabular}{ccc}
\hline \multicolumn{2}{c}{ 13-15 Tahun } & \multirow{2}{*}{ Nilai } \\
\cline { 1 - 2 } Putera & Putri & \\
\hline 38 ke atas & 28 ke atas & 5 \\
\hline 28 - 37 & $19-27$ & 4 \\
\hline $19-27$ & $9-18$ & 3 \\
$8-18$ & $3-8$ & 2 \\
\hline 0 - 7 & $0-2$ & 1 \\
\hline
\end{tabular}

Berdasarkan hasil perhitungan tes awal dan tes akhir baring duduk 60 detik pada sampel diperoleh data sebagai berikut:

Tabel 6

Hasil Penghitungan Nilai Rata-Rata dan Simpangan Baku Tes Baring Duduk 60 detik

\begin{tabular}{cccccc}
\hline \multirow{2}{*}{ Baring duduk 60 detik } & \multirow{N}{*}{} & \multicolumn{2}{c}{ Tes Awal } & \multicolumn{2}{c}{ Tes Akhir } \\
\cline { 3 - 6 } & & $\begin{array}{c}\text { Rata- } \\
\text { rata }\end{array}$ & $\begin{array}{c}\text { Simpangan } \\
\text { baku }\end{array}$ & $\begin{array}{c}\text { Rata- } \\
\text { rata }\end{array}$ & $\begin{array}{c}\text { Simpangan } \\
\text { baku }\end{array}$ \\
\hline Latihan Sirkuit 5 Pos & $\mathbf{2 0}$ & $\mathbf{3 0 , 0 0}$ & $\mathbf{4 , 0 0}$ & $\mathbf{3 3 , 1 0}$ & $\mathbf{3 , 5 7}$ \\
\hline
\end{tabular}




\section{Tes Loncat Tegak}

Berdasarkan hasil perhitungan tes loncat tegak dideskripsikan dalam norma penilaian pada tabel sebagai berikut:

Tabel 7. Norma Penilaian Tes Loncat Tegak

\begin{tabular}{ccc}
\hline \multicolumn{2}{c}{ 13 - 15 Tahun } & \multirow{2}{*}{ Nilai } \\
\cline { 1 - 2 } Putera & Putri & 5 \\
\hline 66 ke atas & 50 ke atas & \\
\hline $53-65$ & $39-49$ & 4 \\
\hline $42-52$ & $30-38$ & 3 \\
\hline $31-41$ & $21-29$ & 2 \\
\hline $0-30$ & $0-20$ & 1 \\
\hline
\end{tabular}

Berdasarkan hasil perhitungan tes awal dan tes akhir loncat tegak pada sampel diperoleh data sebagai berikut:

Tabel 8

Hasil Penghitungan Nilai Rata-Rata dan Simpangan Baku Tes Loncat Tegak

\begin{tabular}{cccccc}
\hline \multirow{2}{*}{ Loncat Tegak } & & \multicolumn{2}{c}{ Tes Awal } & \multicolumn{2}{c}{ Tes Akhir } \\
\cline { 3 - 6 } & N & $\begin{array}{c}\text { Rata- } \\
\text { rata }\end{array}$ & $\begin{array}{c}\text { Simpangan } \\
\text { baku }\end{array}$ & $\begin{array}{c}\text { Rata- } \\
\text { rata }\end{array}$ & $\begin{array}{c}\text { Simpangan } \\
\text { baku }\end{array}$ \\
\hline Latihan Sirkuit 5 Pos & 20 & $\mathbf{4 4 , 5 0}$ & $\mathbf{2 , 3 7}$ & $\mathbf{4 1 , 2 0}$ & 3,61 \\
\hline
\end{tabular}

\section{Tes Lari jarak Jauh 1000 meter}

Berdasarkan hasil perhitungan tes lari jarak jauh 1000 meter dideskripsikan dalam norma penilaian pada tabel sebagai berikut:

Tabel 9. Norma Penilaian Tes Lari Jarak Jauh 1000 meter

\begin{tabular}{ccc}
\hline \multicolumn{2}{c}{ 13-15 Tahun } & \multirow{2}{*}{ Nilai } \\
\cline { 1 - 2 } Putra & Putri & \\
\cline { 1 - 2 } Sd-3.04" & Sd $-3.06 "$ & 5 \\
\hline $3.05 "-3.53 "$ & $3.07 "-3.55 ”$ & 4 \\
\hline $3.54 "-4.46 "$ & $3.56 "-4.58 ”$ & 3 \\
\hline $4.47 "-6.04 "$ & $4.59 "-6.04 "$ & 2 \\
\hline $6.05 "-$ dst & $6.41 "-$ dst & 1 \\
\hline
\end{tabular}

Berdasarkan hasil perhitungan tes awal dan tes akhir lari jarak jauh 1000 meter pada sampel diperoleh data sebagai berikut:

\section{Tabel 10}

Hasil Penghitungan Nilai Rata-Rata dan Simpangan Baku Tes Lari Jarak Jauh 1000 meter

\begin{tabular}{cccccc}
\hline \multirow{2}{*}{ Lari 1000 meter } & & \multicolumn{2}{c}{ Tes Awal } & \multicolumn{2}{c}{ Tes Akhir } \\
\cline { 3 - 6 } & N & $\begin{array}{c}\text { Rata- } \\
\text { rata }\end{array}$ & $\begin{array}{c}\text { Simpangan } \\
\text { baku }\end{array}$ & $\begin{array}{c}\text { Rata- } \\
\text { rata }\end{array}$ & $\begin{array}{c}\text { Simpangan } \\
\text { baku }\end{array}$ \\
\hline Latihan Sirkuit 5 Pos & 20 & 3,73 & 0,42 & 5,59 & 0,41 \\
\hline
\end{tabular}


Langkah selanjutnya adalah melakukan pengujian normalitas. Uji Normalitas data yang digunakan pada penelitian ini menggunakan uji liliefors dengan kriteria uji jika L hitung < L tabel, maka data tersebut berdistribusi normal. Berikut hasil uji normalitas data pada kelompok eksperimen yaitu latihan sirkuit 5 pos yang disajikan pada tabel berikut:

Tabel 11

Hasil Uji Normalitas

\begin{tabular}{ccc}
\hline Nilai Lo & Nilai L - tabel & Kesimpulan \\
\hline 0,1669 & 0,2580 & Normal \\
\hline
\end{tabular}

Berdasarkan tabel di atas dapat diketahui bahwa data tes kelompok eksperimen L-hitung 0,1669 < L-tabel 0,2580 yang berarti data berdistribusi normal, maka dengan demikian pengujian selanjutnya dilakukan dengan penghitungan parametrik.

Langkah pengujian selanjutnya adalah pengujian dan analisis rata-rata, hal ini dilakukan untuk mengetahui apakah terdapat pengaruh hasil latihan setelah mendapatkan treatmen latihan selama 4 minggu, sehingga hasil yang didapat apakah signifikan atau tidak signifikan.

Adapun hasil analisis dan penghitungannya dapat dilihat pada tabel penghitungan di bawah ini:

Tabel 12

Hasil Uji Rata-rata (Uji-t)

Peningkatan Kebugaran Jasmani Dengan Masing-masing Metode Latihan

\begin{tabular}{ccc}
\hline t-Hitung & t-Tabel & Kesimpulan \\
\hline 1,55 & 2,23 & Signifikan \\
\hline
\end{tabular}

Pengujian untuk peningkatan latihan di atas dilakukan dengan pengujian rata-rata dua pihak atau yang disebut dengan uji t. Berdasarkan pada penghitungan dan analisi nilai t-hitung yang diperoleh, maka didapat nilai t-hitung yang lebih besar dari t-tabel pada tingkat kepercayaan atau taraf nyata $\alpha=0.05$ dengan $\mathrm{dk}(\mathrm{n} 1+\mathrm{n} 2-2)=18$, dimana harga $\mathrm{t}(1-1 / 2 \alpha)$, dalam daftar distribusi diperoleh harga t-tabel sebesar 2.23. Maka pengujian tersebut signifikan artinya latihan sirkuit 5 pos memberikan pengaruh yang signifikan terhadap tingkat kebugaran jasmani siswa kelas 8A SMP Padalarang Kabupaten Bandung Barat. 


\section{Pembahasan}

Kebugaran jasmani merupakan unsur penting bagi siswa Sekolah Menegah Pertama (SMP) sehingga dapat dibina agar fisik kuat dan mempunyai kesegaran jasmani yang baik, sehingga dapat melakukan tugas sekolah dengan baik, Kebugaran jasmani sangat penting fungsinya bagi siswa dikarenakan segala aspek perkembangan tubuh, peningkatan kebugaran jasmani di lingkungan sekolah. Kebugaran mengacu pada kondisi fisiologis yang memungkinkan seseorang untuk memenuhi tuntutan kehidupan sehari-hari atau yang memberikan dasar bagi kinerja sebuah aktivitas(Latar \& Tomasoa, 2020).

Siswa dengan kebugaran jasmani yang baik, tidak akan cepat mengalami kelelahan, sehingga kondisi tersebut dapat mendukung anak dalam melakukan aktivitas gerak. Dengan kondisi tubuh yang baik akan sangat mendukung aktivitas pembelajaran, sehingga siswa akan tetap semangat dalam mengikuti pembelajaran. Kebugaran jasmani siswa yang baik akan menjamin kesiapan siswa dalam melaksanakan tugas sehari-hari dan selalu menampakkan penampilan yang optimal. Semakin terpelihara kesehatan ditunjukkan dengan semakin baiknya kondisi kebugaran jasmani seseorang. Kebugaran jasmani atau kesegaran jasmani akan mendukung dalam menjalankan aktivitas sehari-hari. Peningkatan kebugaran jasmani dapat tingkatkan dengan olahraga atau kegiatan rutin (Sinuraya \& Barus, 2020).

Dari hasil pengolahan dan analisis data dengan pendekatan statistik terhadap perbedaan pengaruh antara latihan circuit 5 pos dan latihan cross country terhadap tingkat kebugaran jasmani siswa SMP Padalarang Kabupaten Bandung Barat, latihan ini dapat memberikan pengaruh yang signifikan terhadap tingkat kebugaran jasmani siswa SMP Padalarang Kabupaten Bandung Barat. Hal ini disebabkan pada metode latihan dengan metode ini terdapat efesiensi yang relevan terhadap kondisi fisik yang dibutuhkan untuk kebugaran jasmani. Keuntungan dari metode latihan ini salah satunya adalah dapat meningkatkan kebugaran jasmani siswa.

Latihan circuit 5 pos merupakan bentuk latihan dengan memberikan treatman latihan berupa beberapa tugas gerak yang dilakukan dalam satu rangkaian latihan. Secara fungsi faal, dari beberapa bentuk latihan circuit 5 pos ini terdapat fungsi untuk meningkatkan kemampuan fungsional tubuh yang menyeluruh, seperti di antaranya kemampuan cardiovascular, kemampuan otot tubuh, serta peningkatan kemampuan fisik dalam tubuh (Andrian Fahmi1, Muhammad Suhdy2, 2021). Dengan demikian bentuk latihan circuit 5 pos ini bermanfaat dalam meningkatkan tingkat kebugaran jasmani khususnya untuk usia anak sekolah menengah pertama. 
Dengan demikian, metode latihan sirkuit memberikan pengaruh yang signifikan terhadap peningkatan kebugaran jasmani, dimana terlihat ada perbedaan yang signifikan dari hasil tes awal (pre-test) yang dilakukan sebelum eksperimen dengan metode latihan sirkuit 5 pos dengan tes akhir (pos-test) setelah ekperimen (treatment/perlakuan) yang diberikan terhadap tingkat kebugaran siswa. Latihan sirkuit ini harus merupakan siklus sehingga tidak membosankan. Metode sirkuit dalam penelitian ini dengan 5 pos; Pos (1) push up; Pos (2) sit up; Pos (3) jumping jack; Pos (4) mountain climber; Pos (5) wall sheet. Dilakukan 4 set, lama pembebanan 30 detik setiap pos, istirahat 30 detik antar pos 5 menit antar set. Latihan sirkuit akan tercakup latihan untuk meningkatkan kondisi fisik diantaranya kekuatan, ketahanan, kelentukan, kelincahan, keseimbangan, dan ketahanan jantung paru. Dalam hal ini latihan sirkuit 5 pos training meningkatkan kebugaran jasmani siswa (Rustiawan, 2020).

\section{KESIMPULAN}

Berdasarkan hasil penelitian dan analisis data yang didapat maka dapat disimpulkan bahwa latihan sirkuit 5 pos memberikan pengaruh yang signifikan terhadap peningkatan kebugaran jasmani siswa SMP Padalarang Kabupaten Bandung Barat pada masa pandemi dengan rata-rata kategori sedang dilihat dari hasil 5 item tes kebugaran jasmani. Penelitian ini bisa menjadi masukan bagi sekolah agar meningkatkan aktivitas fisik siswa, serta bisa menjadi motivasi siswa saat pandemi ini agar siswa lebih semangat saat melakukan aktivitas fisik untuk kedepannya dalam upaya meningkatkan imun dimasa pandemi ini.

\section{DAFTAR PUSTAKA}

Afdinda, R., Saputra, E., Iqroni, D., Jambi, U., Olahraga, J., \& Indonesia, K. (2021). Jurnal Olahraga \& Kesehatan Indonesia available online at https://jurnal.stokbinaguna.ac.id/index.php/jok KONTRIBUSI POLA HIDUP SEHAT DAN CIRCUIT TRAINING. 1, 136-142.

Ahmed, M. D., van Niekerk, R. L., Ho, W. K. Y., Morris, T., Baker, T., Ali Khan, B., \& Tetso, A. (2018). Female student athletes' perceptions of acceptability and the occurrence of sexual-related behaviour by their coaches in India. International Journal of Comparative and Applied Criminal Justice, 42(1), 33-53. https://doi.org/10.1080/01924036.2017.1310661

Alficandra, Suganda, M. A., \& Yani, A. (2019). Pengaruh Metode Latihan Sirkuit terhadap Daya Tahan Kekuatan Otot Tungkai Pemain Persatuan Sepakbola 
Batusasak Kecamatan Kampar Kiri Hulu Kabupaten Kampar. In Prosiding Seminar Nasional Pascasarjana (PROSNAMPAS), 44-452.

Andrian Fahmi1, Muhammad Suhdy2, H. R. (2021). Pengaruh metode circuit training terhadap kebugaran jasmani pada klub sepakbola. 1, 50-53.

Ariestika, E., Widiyanto, \& Agung Nanda, F. (2021). Jurnal Sains Olahraga dan Pendidikan Jasmani. Sains Olahraga Dan Pendidikan JasmaniI, 21, 1-10. http://sportscience.ppj.unp.ac.id/index.php/jss/article/download/58/64

Bile, R. L., \& Tapo, Y. B. O. (2021). Pelatihan Program Olahraga Kesehatan Untuk Pemeliharaan Kebugaran Jasmani Siswa Sma Di Masa Pandemi Covid-19. Jurnal Abdimas Ilmiah Citra Bakti, 2(1), 41-49. https://doi.org/10.38048/jailcb.v2i1.187

Chen, W., Hammond-Bennett, A., Hypnar, A., \& Mason, S. (2018). Health-related physical fitness and physical activity in elementary school students. BMC Public Health, 18(1), 1-12. https://doi.org/10.1186/s12889-018-5107-4

Ennis, C. D. (2017). The influence of value orientations in curriculum decision making. Quest, 44(3), 317-329. https://doi.org/10.1080/00336297.1992.10484058

Ickes, M. J., McMullen, J., Pflug, C., \& Westgate, P. M. (2016). Impact of a Universitybased Program on Obese College Students' Physical Activity Behaviors, Attitudes, and Self-efficacy. American Journal of Health Education, 47(1), 47-55. https://doi.org/10.1080/19325037.2015.1111178

Latar, I. M., \& Tomasoa, J. J. . (2020). Pengaruh Tingkat Kebugaran Jasmani Terhadap Hasil Belajar Bola Basket Mahasiswa Program Studi Penjaskesrek Angkatan 2018. Jurnal Ilmiah Wahana Pendidikan, 6(3), 295-307. https://doi.org/10.5281/zenodo.3973777

Maksum. (2012). Metodologi Penelitian dalam Olahraga. 53(9), 1689-1699.

Murtiningsih, M. (2020). Penyuluhan Kesehatan Pola Hidup Sehat Secara Daring menggunakan Zoom dan Youtube Sebagai Media Ajar pada Masa Pandemi COVID-19. Jurnal Pengabdian Nasional (JPN) Indonesia, 1(2), 37-40. https://doi.org/10.35870/jpni.v1i2.13

Purba, Jumesli, Atri Widowati, W. J. D. (2020). Peningkatan Kebugaran Jasmani Melalui Variasi Latihan Sirkuit dan Olahraga Aerobik. 3(2017), 54-67. http://repositorio.unan.edu.ni/2986/1/5624.pdf

Rustiawan, H. (2020). Pengaruh Latihan Interval Training Dengan Running Circuit Terhadap Peningkatan Vo2Max. Jurnal Wahana Pendidikan, 7(1), 15. https://doi.org/10.25157/wa.v7i1.3108

SHAPE America. (2015). The essential Components of Physical Education. The Essential 
Journal of Physical and Outdoor Education, 3 (2) 2021 | 167-178

ISSN : 2721-9992 (Online)

ISSN : 2656-1883 (Print)

$\begin{array}{lllll}\text { Components of } & \text { Physical }\end{array}$

https://www.shapeamerica.org/upload/TheEssentialComponentsOfPhysicalEducatio n.pdf?fbclid=IwAR1eAr05bIwQ6rXDHz7PnhvDxKXRqnMnSdQgZF9qFnL3jrOU $2 \operatorname{tvgsLljZ30~}$

Sinuraya, J. F., \& Barus, J. B. N. B. (2020). Tingkat Kebugaran Jasmani Mahasiswa Pendidikan Olahraga Tahun Akademik 2019/2020 Universitas Quality Berastagi. Kinestetik, 4(1), 23-32. https://doi.org/10.33369/jk.v4i1.10359

Sukur, A., Amin, B. F., \& Arif, M. (2020). Edukasi Olahraga Dan Kesehatan Masyarakat Di Masa Pandemi Covid-19. ... Pengabdian Kepada Masyarakat, 2020, 134-144. http://journal.unj.ac.id/unj/index.php/snppm/article/view/19629 